Article

\title{
Blocking and Deblocking of Diisocyanate to Synthesize Polyurethanes
}

\section{Sourita Jana ${ }^{1,2}$, Debasis Samanta ${ }^{2}$, Mir Muhammad Fahad ${ }^{3}$, Sellamuthu N. Jaisankar 1,2,3,* Hongdoo Kim ${ }^{3, *}$}

1 Polymer Science \& Technology Division,

CSIR-Central LeatherResearch Institute, Adyar,Chennai-600020, India

2 University of Madras, Chennai-600005,India

3 Department of Advanced Materials Engineering for Information and Electronics,

College of Engineering, Kyung Hee University, Yongin-si, Gyeonggi-do, South Korea

* Correspondence: snjsankar@clri.res.in, snjaio@yahoo.com, hdkim@khu.ac.kr

\begin{abstract}
Diisocyanates, particularly toluene diisocyanate (TDI) are useful for the preparation of various polyurethanes with specific applications as leather-like materials, adhesives, insoles etc. Blocking agents can be used for the operational simplicity and reducing the hazards of TDI. In this paper we reported the use of 3-(4-bromo-phenyl)-1H-pyrazole to block toluene diisocyanate (TDI). FTIR, NMR, thermogravimetric analysis, contact angle and differential scanning calorimetry (DSC) and were used for characterization. Effectiveness of blocking was confirmed by spectroscopic techniques. DSC thermogram shows that blocked adducts deblock at $240{ }^{\circ} \mathrm{C}$ causing the regeneration of TDI and blocking agents to react with polyols of different molecular weights forming polyurethanes. The characterization of polyurethanes has been done by Infrared spectroscopy, Nuclear magnetic resonance spectroscopy, thermogravimetric analysis, differential scanning calorimetry and contact angle study.
\end{abstract}

Keywords: Toluene diisocyanate, 3-(4-bromophenyl)-1H-pyrazole, blocking agent, blocked adduct, deblocks, polyol, polyurethane, coatings.

\section{Introduction}

Polyurethanes are usually prepared by the step growth polymerization of diisocianates and diols or polyols.[1] Since some of the diisocyanates are hazardous, it can be blocked with compounds having active hydrogen so that it can be unblocked in presence of diols to produce polyurethanes.[2] Very recently, different compounds have been used as blocking agents such as pyrazoles, indoles etc.[3] Recently, 2-Formyloxyethyl methacrylate, a liquid blocking agent has been used to block different isocyanates.[4] 2,4-Toluene diisocyanate has been blocked with imidazole, 2-methylimidazole, 2-Phenyl-imidazole.[5] In this case, addition of isocyanates with active hydrogen compounds like alcohols, amines, thiols etc. leads to the formation of urethane, urea, thiourethane and amides. Among those, thiols react with isocyanates in a slower rate than alcohols and amines[6] Phenol-, 2-naphthol-, and 1-nitroso-2-naphthol were used as blocking agents to block toluene diisocyanate (TDI) and isophorone diisocyanate (IPDI). The 2-naphthol-blocked diisocyanate adducts were thermally less stable than the phenol-blocked diisocyanates adducts. The introduction of nitroso group in the blocking agent reduces dissociation temperature. $\varepsilon$-caprolactam has been widely used as an effective blocking agent for isocyanates.[7] Polyisocyanates blocked with caprolactam represent a commercially important class of polyols. The dissociation temperature of a polyisocyanate blocked with $\varepsilon$-caprolactam is ranged between $130^{\circ} \mathrm{C}$ and $160^{\circ} \mathrm{C}$. [8] Further, malonate, oximes etc have been reported as blocking agents for isocyanate.[9,10] Sodium bisulfite blocked isophorone diisocyanate is water soluble and stable for more than 12 months at room temperature both in liquid and solid state.[11] The blocking of polymethylenepolyphenylisocyanate 
(PAPI) had been done by using sodium bisulfate[12]. Among different blocking agents, pyrazole-based blocking agents have attracted special attentions because of their effectiveness in blocking as well as deblocking.[13] The deblocking reactions of pyrazoleblocked isocyanate proceed through five-center complex formation.[12,14] In this context, a group of water-dispersible blocked polyisocyanates were synthesized from toluene 2,4diisocyanate (TDI) and isophorone diisocyanate (IPDI), using ethyl cellosolve (EC), epsilon-caprolactam (CL) and methyl ethyl ketoxime (MEKO) as blocking agents in presence of dimethylol propionic acid.[15] The aqueous dispersions of the adducts offer good storage stability. The initial deblocking temperature of the adducts are at about 55-85 ${ }^{\circ} \mathrm{C}$. Further, methyl anacardate, secondary butyl anacardate and cardanol-N-hydroxyphthalimide (NHPH) were separately used as blocking agents to block 2,4-toluene diisocyanate.[16] Aqueous polyurethane dispersions have been prepared from castor oil[17] and polyurethane coating with better adhesion and anticorrosion protection, synthesized from blocked isocyanate has been reported recently.[18] Along the line, toluene diisocyante (TDI), isophoronediisocyanate (IPDI), hexamethylenediisocyanate (HDI), 4,4'-diphenylmethanediisocyanate (MDI) blocked with 2-butoxyethanol has been reported separately.[19]

Efficacy of the formation of blocked isocyanate depends on structures of the isocyanate and blocking agent, thermal stability of the isocyanate-blocking agent bond and catalysis.[20] Along the same line, isocyanates were blocked with methyl ethyl ketoxime (MEKO) and bisulfite (BS), for fabrication of DNA microarrays.[20] Isocyanates like hexamethyelenediisocyanate, diphenylmethane diisocyanate, isophorone diisocyanate, can also be blocked with diethylene glycol monobutyl ether.[21] Imidazole blocked 2,4-toluene diisocyanate with polyethylene glycol, has been synthesized and characterized with DSC, TGA, DMA and glass transition temperature.[22] Further, alkyl-pyrazole has been studied as blocking agent[23] and polyurethanes have been synthesized from 4bromo-1H-pyrazole-blocked HMDI.[13] polyurethane composites with nanomaterials have been reported by our group recently.[24-27]

Although blocked isocyanates are useful for their non-hazardous methods, the stability and environment-friendliness of polyurethane elastomers depends on the use of aromatic or aliphatic isocyanates and chain extenders like diols, triols, anddiamines.[28] The recyclability, and their properties have been studied in a few cases.[29] Further, the degradation of polyurethane elastomers can happen in the ways of photo-thermal, ozonolytic, hydrolytic, chemical, enzymatic, in-vivo/in-vitro oxidative, biological, and mechanical degradation.[30] Recently we reported that biodegradable polyurethane foam is used in foot ware to reduce waste.[31]

In this paper, we reported an efficient method of blocking diisocyanates to prepare polyurethanes using biocompatible polyethylene glycol. De-blocking and polyurethane formations were performed in a simple operation without using any organic solvent. The polyurethanes were successfully used as coating agents to improve hydrobhobicity.

\section{Materials and Methods}

Toluene diisocyanate, polyethylene glycol-400 (PEG-400), PPG-1000, PPG-2000 and PPG3000 were purchased from sigma-aldrich, 4-(3-bromophenyl)-1H-pyrazole from TCI, dibutyltindilaurate (DBTDL) from fulka SG and used as received. Solvents like chloroform, hexane are purchased from emparta ER and used after purification.

Toluene diisocyanate (TDI) was reacted with 3-(4-bromophenyl)-1H-pyrazole as blocking agent to form blocked isocyanate adducts. NMR, IR, TGA, DSC were used to characterize the materials and to investigate the deblocking temperature. At deblocking temperature, regenerated toluene diisocyanate was reacted with polyols of different molecular weight to form polyurethane. Scheme-1 describes blocking reactions of isocyanates with 
3-(4-bromo-phenyl)-1H-pyrazole. Scheme-2 describes the reactions of blocked TDI with 3-(4-bromo-phenyl)-1H-pyrazole with polyols.
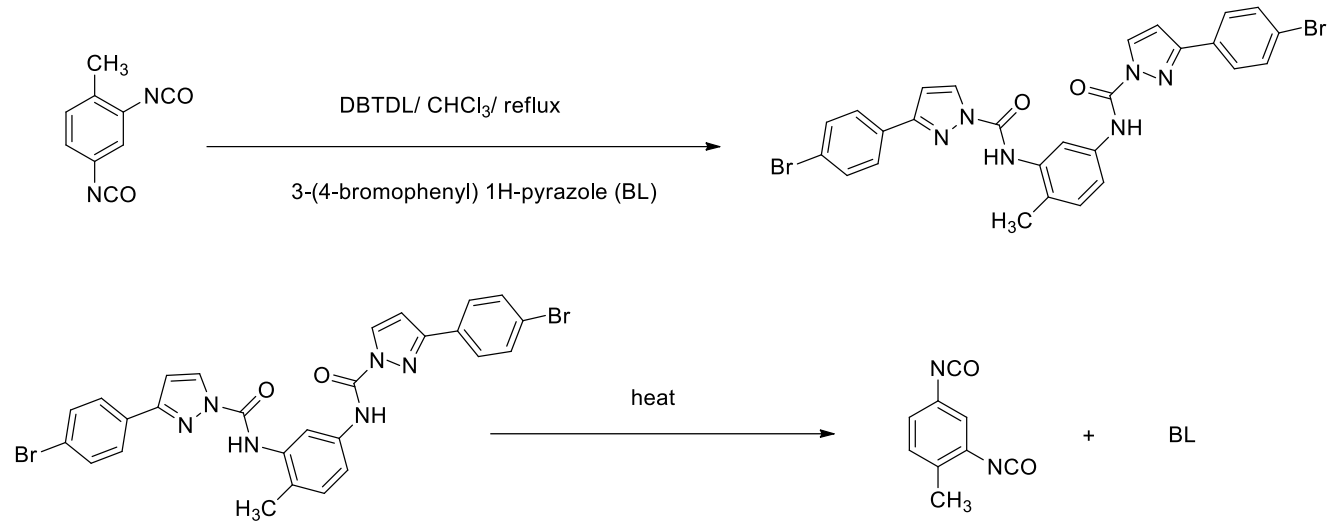

Scheme-1. Blocking reactions of isocyanates with 3-(4-bromophenyl)-1H-pyrazole.

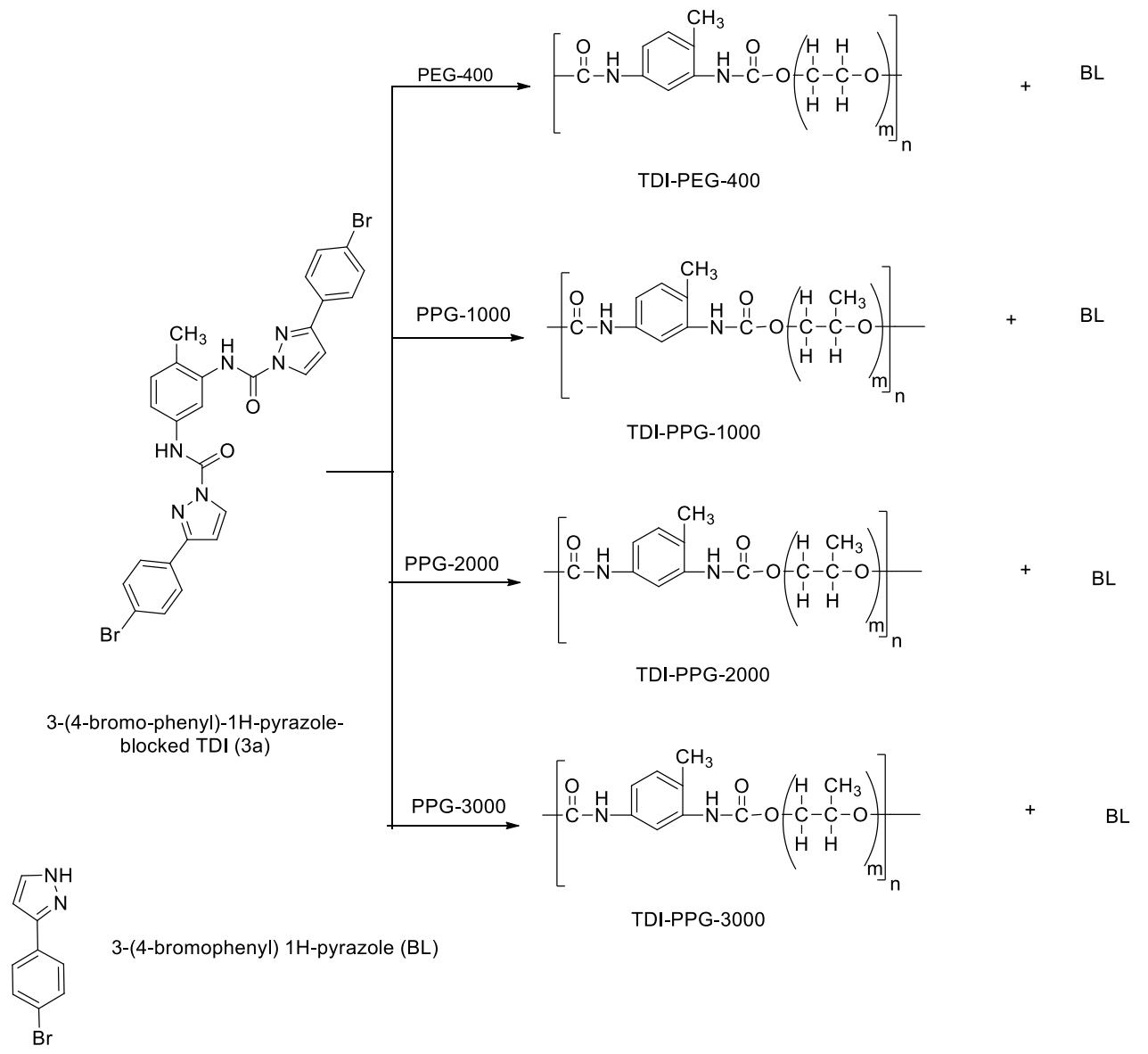

Scheme-2. Reactions of 3-(4-bromo-phenyl)-1H-pyrazole-blocked-Toluene diisocyanate with polyols 


\subsection{Synthetic procedure of 4-(3-Bromophenyl)-1H-pyrazole-blocked Toluene diisocya-} nate adducts.

The $4.48 \times 10^{-4} \mathrm{~mol}(0.1 \mathrm{~g})$ of blocking agent and $2.24 \mathrm{~mol}(0.03 \mathrm{ml})$ of TDI has been taken in a $50 \mathrm{ml}$ single necked round bottomed flask along with porceline beads and dissolved in $15 \mathrm{ml}$ of solvent. TDI has been added with a micropipette. 0.54 weight percent of Dibutyltin dilaurate is added with micropipette using $0.001 \%$ of DBTDL. Guard tube was attached to it and after refluxing, the round bottom flask has been allowed to cool to room temperature. Then content of round bottom flask has been reduced in volume and transferred in a beaker, hexane was added for precipitation and kept in room temperature at $28^{\circ} \mathrm{C}$. The precipitation was filtered and it was washed with hexane and dried in oven at $60{ }^{\circ} \mathrm{C}$ for 6 hours. For purification, the adduct was dissolved in chloroform and precipitated with hexane in room temperature.

2.2. Synthetic procedure for the preparation of polyurethane from 4-(3-bromophenyl)1H-pyrazole-blocked TDI adducts.

The $3.08 \times 10^{-4}$ moles (0.19 gram) of 3-(4-bromophenyl-1H-pyrazole-blocked-toluenediisocyanates and $3.08 \times 10^{-4}$ moles ( 0.307 gram) polyethers has been taken in a beaker with narrow diameter and kept in oven at temperature $240{ }^{\circ} \mathrm{C}$ for 4 hours. After that the beaker was taken out of the oven in cold condition. Then the sample is set in a soxhlet apparatus using $500 \mathrm{ml}$ pet ether and heating for 5h. 4-(3-Bromophenyl)-1H-pyrazole-blocked TDI adduct have been synthesized in different condition like different catalytic concentration, solvent and reflux time, as described in Table- 1 and reaction condition of polyurethane synthesis is described in Table-2.

Table-1. Synthesis of 4-(3-bromophenyl)-1H-pyrazole-blocked TDI adduct

\begin{tabular}{llllllll}
\hline $\begin{array}{l}\text { S. } \\
\text { No. }\end{array}$ & TDI & $\begin{array}{l}\text { Blocking } \\
\text { agent } \\
\text { (gram) }\end{array}$ & $\begin{array}{l}\text { Adduct } \\
\text { (gram) }\end{array}$ & $\begin{array}{l}\text { Solvent } \\
\mathbf{X ~ 1 0 - 4}\end{array}$ & $\begin{array}{l}\text { Reflux } \\
\text { Time } \\
\text { (hour) }\end{array}$ & $\begin{array}{l}\text { Catalyst } \\
\text { DBTDL }\end{array}$ & $\begin{array}{l}\text { Yield (\%) } \\
(\mathbf{w t} \%)\end{array}$ \\
\hline 1. & 3.9 & 0.10 & 0.13 & $\mathrm{CHCl}_{3}$ & 3.0 & 0.85 & 91 \\
& & & & & & & \\
2. & 3.9 & 0.10 & 0.12 & $\mathrm{CHCl}_{3}$ & 3.0 & 0.65 & 85 \\
3. & 3.9 & 0.10 & 0.12 & $\mathrm{CHCl}_{3}$ & 3.0 & 0.50 & 88 \\
4. & 3.9 & 0.10 & 0.11 & $\mathrm{CHCl}_{3}$ & 3.0 & 1.0 & 81 \\
\hline
\end{tabular}


Table-2. Reaction conditions of polyurethane from 4-(3-bromophenyl)-1H-pyrazole-blocked TDI adduct

\begin{tabular}{|c|c|c|c|c|c|c|c|c|}
\hline $\begin{array}{l}\text { S. } \\
\text { No. }\end{array}$ & $\begin{array}{l}\text { Wt. of } \\
\text { blocked } \\
\text { adduct } \\
\text { (gram) }\end{array}$ & polyether & $\begin{array}{l}\text { Wt of } \\
\text { poly- } \\
\text { ether } \\
\text { (gram } x \\
10^{-4} \text { ) }\end{array}$ & $\begin{array}{l}\text { Polyure- } \\
\text { thane }\end{array}$ & $\begin{array}{l}\text { Wt of } \\
\text { Polyu- } \\
\text { rethane } \\
\text { gram }\end{array}$ & $\begin{array}{l}\text { Yield } \\
(\%)\end{array}$ & $\begin{array}{l}\text { Temp. } \\
\left({ }^{\circ} \mathrm{C}\right)\end{array}$ & $\begin{array}{l}\text { Gelation } \\
\text { Time (h) }\end{array}$ \\
\hline 1. & 0.10 & PEG-400 & 6.44 & $\begin{array}{l}\text { TDI-PEG- } \\
400\end{array}$ & 0.061 & 95 & 240 & 3 \\
\hline 2. & 0.19 & PPG-1000 & 3.22 & $\begin{array}{l}\text { TDI-PPG- } \\
1000\end{array}$ & 0.175 & 34 & 240 & 4 \\
\hline 3. & 0.1 & PPG-2000 & 3.22 & $\begin{array}{l}\text { TDI-PPG- } \\
2000\end{array}$ & 0.13 & 32 & 240 & 4 \\
\hline 4. & 0.1 & PPG-3000 & 4.83 & $\begin{array}{l}\text { TDI-PPG- } \\
3000\end{array}$ & 0.18 & 32 & 240 & 4 \\
\hline
\end{tabular}

\subsection{Spectroscopic and thermal analysis}

Nicolet Impact 400 spectrometer is used to record FT-IR spectra. Before recording compound spectra, the background spectrum was taken. ${ }^{1} \mathrm{H}$ and ${ }^{13} \mathrm{C}$ NMR spectra has been done with $\mathrm{CDCl}_{3}$ solvent on JEOL $500 \mathrm{MHz}$ ECA instrument at room temperature. For the ${ }^{13} \mathrm{C}$ NMR and DEPT-135, the spectroscopic studies have been done with an operating frequency of $106 \mathrm{MHz}$.The ppm unit is used to express chemical shift. For thermogravimetric analysis instrument,Netzsch with model name STA $449 \mathrm{~F} 3$ jupiter has been used with heating rate $15{ }^{\circ} \mathrm{C} / \mathrm{min}$ and samples run from $25{ }^{\circ} \mathrm{C}$ to $600{ }^{\circ} \mathrm{C}$. For DSC analysis, differential scanning calorimetry instrument of Netzsch with model name DSC 214 Polyma has been used. In case of organic sample, heating rate is $10^{\circ} \mathrm{C} / \mathrm{min}$. and temperature range is $25^{\circ} \mathrm{C}$ to $300{ }^{\circ} \mathrm{C}$. In case of polymer sample, heating rate of sample is $5{ }^{\circ} \mathrm{C} / \mathrm{min}$ and temperature is from $-35{ }^{\circ} \mathrm{C}$ to $280{ }^{\circ} \mathrm{C}$. Contact angle meter version 8.0 of Holmarcopto mechatronics has been used for contact angle analysis.

\section{Results}

The reaction of TDI with 3-(4-bromophenyl)-1H-pyrazole provided the blocked adduct with an yield of $91 \%$. Since DSC predicted the deblocking temperature at $240^{\circ} \mathrm{C}$ simultaneous polymerization has been done at this temperature. In gelation time study, the trend was observed as TDI-PEG-400 adduct $<$ TDI-PPG-1000 TDI-PPG-2000 TDI-PPG-3000. In case of yield of polyurethane from 3-(4-bromophenyl)-1H-pyrazole-TDI the trend followed as TDI-PEG-400 adduct > TDI-PPG-1000 adduct > TDIPPG-2000 TDI-PPG-3000. 


\subsection{NMR Analysis}

Table-3 shows NMR spectral data of blocked adducts and Figure-1 show ${ }^{1} \mathrm{H}$ NMR and ${ }^{13} \mathrm{C}$ NMR of 3(4-bromophenyl)-1H-pyrazole-blocked TDI. Table -4.Shows NMR spectra of polyurethane from blocked TDI with 3-(4-bromophenyl)-1H-pyrazole. The NMR data supported the structures of blocked adduct and polyurethanes.

Table-3. NMR spectra of blocked adduct

\begin{tabular}{|c|l|l|}
\hline Compound & \multicolumn{1}{|c|}{${ }^{1} \mathbf{H}$ NMR (in ppm) } & \multicolumn{1}{c|}{${ }^{13} \mathrm{C}$ NMR (in ppm) } \\
\hline & $2.43(\mathrm{CH}-7), 6.69(2 \mathrm{H}-10), 7.51$ & $16.93\left(\mathrm{CH}_{3}-7\right), 108(\mathrm{C}-5), 127.18$ \\
\end{tabular}
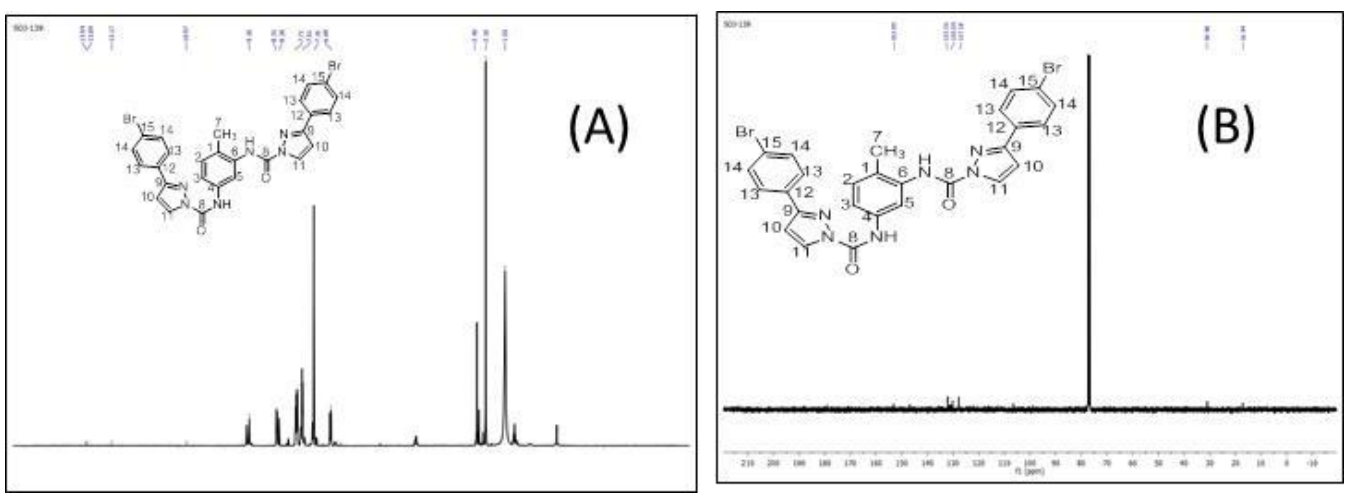

Figure-1. (A) ${ }^{1} \mathrm{H}$ NMR (B) ${ }^{13} \mathrm{C}$ NMR of 3-(4-bromophenyl)-1H-pyrazole-blocked TDI 
Table -4. NMR spectra of polyurethane from blocked TDIwith3-(4-bromophenyl)-1H-pyrazole

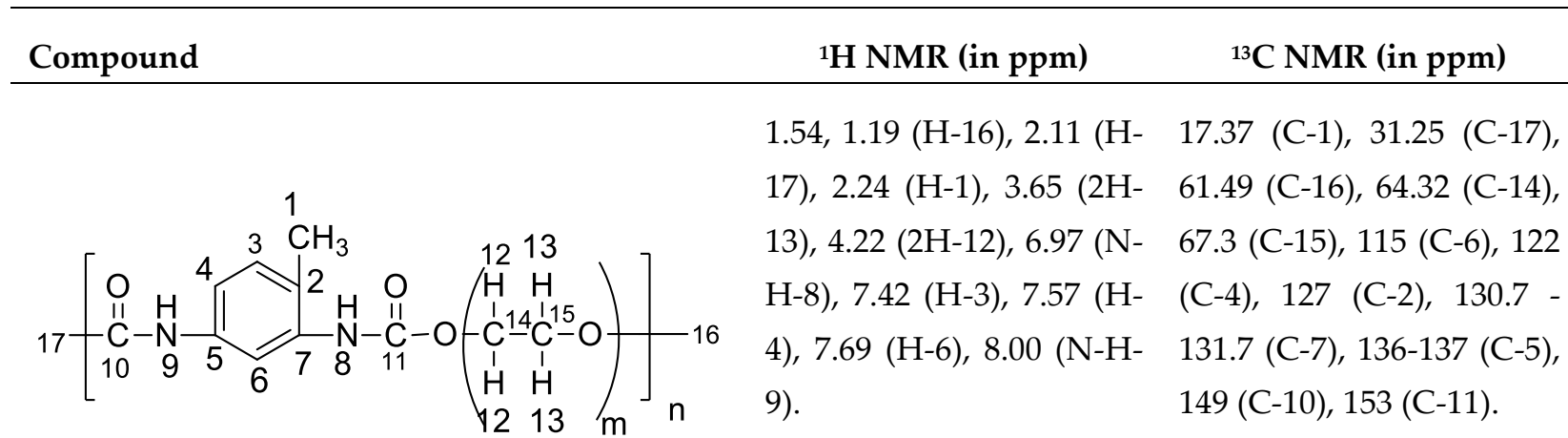

TDI-PEG-400

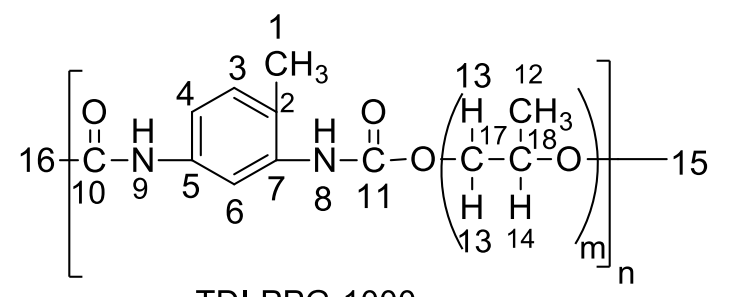

TDI-PPG-1000

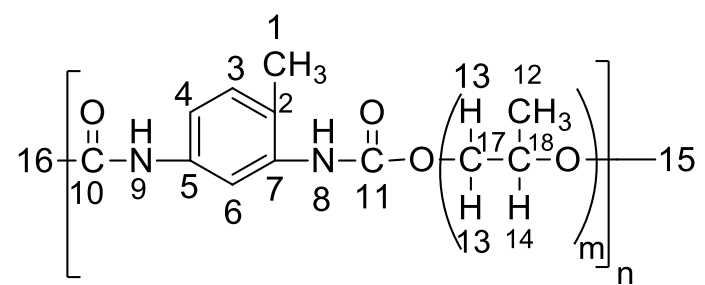

TDI-PPG-2000

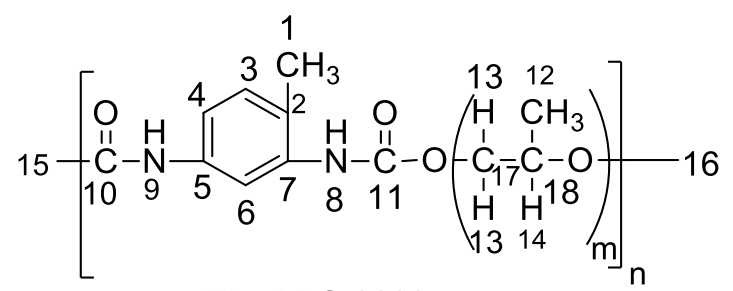

TDI-PPG-3000
$1.10(\mathrm{H}-15), 1.24(\mathrm{H}-12), 17.28$ (C-15,C-1), 29.64 (C-

$2.14(\mathrm{H}-1), 3.34$ (H-14), 16), $72.8(\mathrm{C}-15), 73$ (C-17),

3.47 (H-13), 6.51 (H-9), 7.275 (C-18), 127 (C-4, C-6), (H-3), 7.48 (H-4), 7.56 (H- 131.8 (C-7, C-5).

6), $8.01(\mathrm{H}-8)$

1.15 (H-15), 1.23 (H-12), 17.2 (C-15), 22.62 (C-1), 2.06, 2.26 (C-1), 3.41 (2H- 28.29 (C-12), 45 (C-16), 13), 3.55 (H-14), 7.51 (H-3, 72.75 (C-17), 75 (C-18), 127 $\mathrm{H}-4), 7.65$ (H-6), 8.09 (H- (C-4,C-6), 131 (C-7,C-5), $8, \mathrm{H}-9)$. 170 (C-10), 196 (C-11).

1.06 (H-16), 1.19 (H-12), 17.3 (C-1), 17.4 (C-12), 22 3.33 and $3.45(2 \mathrm{H}-13), 4.12$ (C-16), 31 (C-17), 73, (H-14), 7.45 (H-3, H-4), 127.28 (C-5,C-7), 131 (C7.54 (H-6), 8.01 (N-H-9). 3, C-4, C-6). 

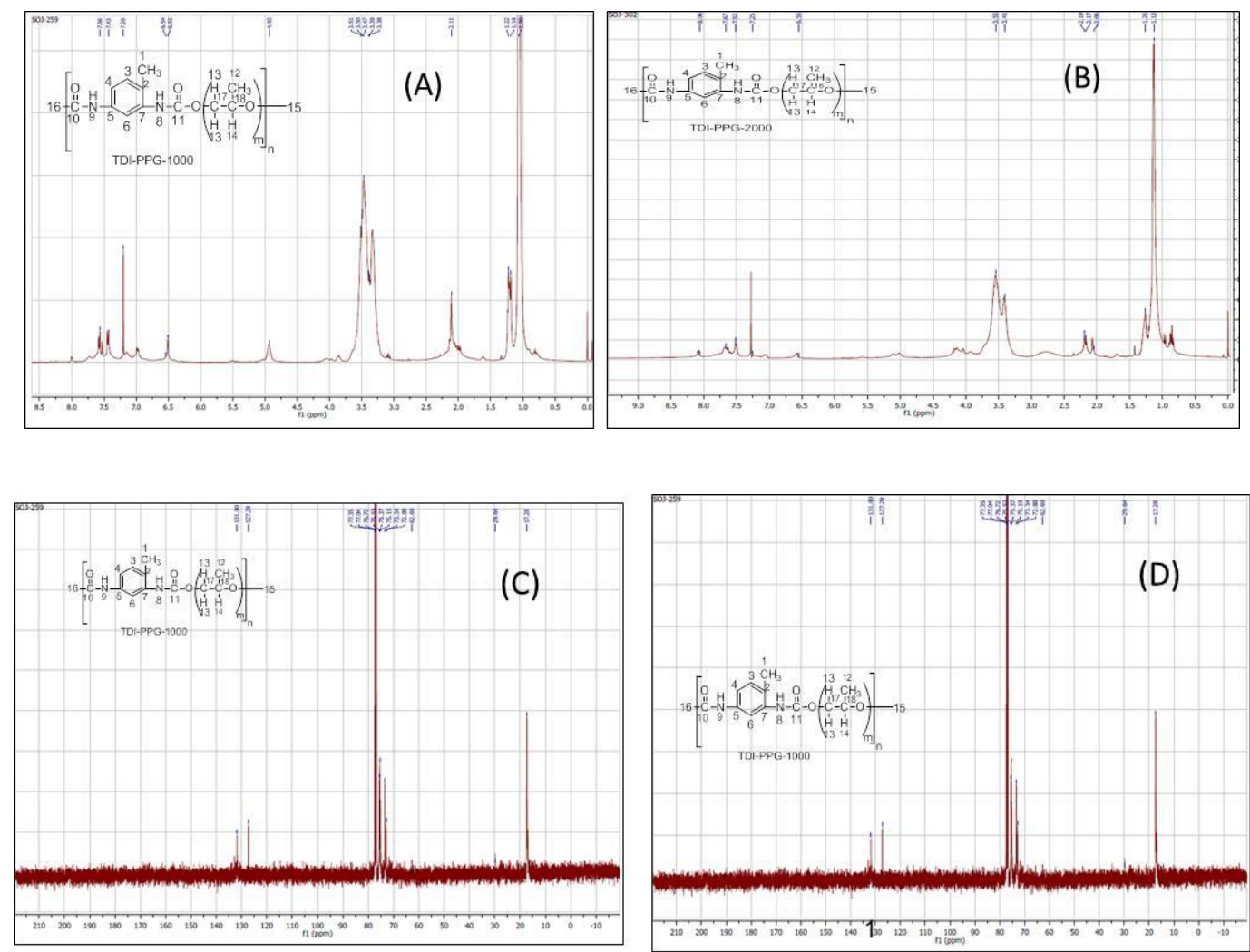

Figure-2. (A) ${ }^{1} \mathrm{H}$ NMR spectrum of TDI-PPG-1000 (B) ${ }^{1} \mathrm{H}$ NMR spectrum of TDI-PPG-2000 (C) ${ }^{13} \mathrm{C}$ NMR spectrum of TDI-PEG-400 (D) ${ }^{13} \mathrm{C}$ NMR spectrum of TDI-PPG-2000

\subsection{DEPT-135}

Distortionless enhancement by polarization transfer (DEPT) has been used to separately identify the signals of methyl (CH3), methylene (CH2), and methine $(\mathrm{CH})$. In DEPT spectra, with methyl (CH3) and methyne $(\mathrm{CH})$ carbons are up and methene $(\mathrm{CH} 2)$ carbons are down. Table-5 represents DEPT spectra of polyurethane from 3-(4-bromophenyl)-1H-pyrazole-blocked TDI. Figure-3 describes DEPT-135 spectra of polyurethane.

Table-5. DEPT-135 spectral data of polyurethane from 3-(4-bromophenyl)-1H-pyrazole-blocked TDI.

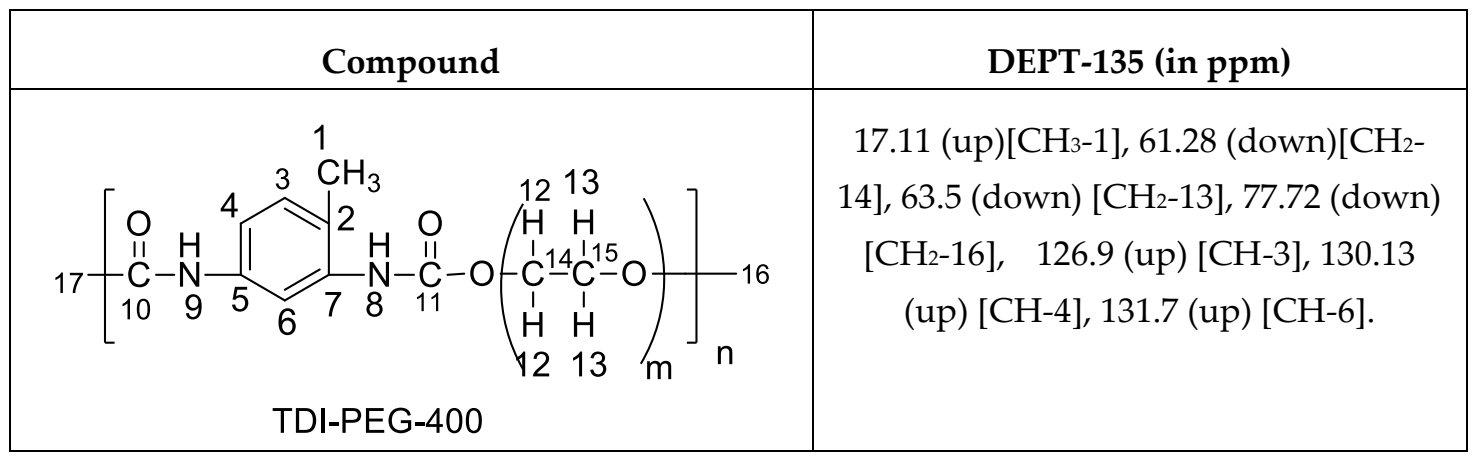




\begin{tabular}{|c|c|}
\hline 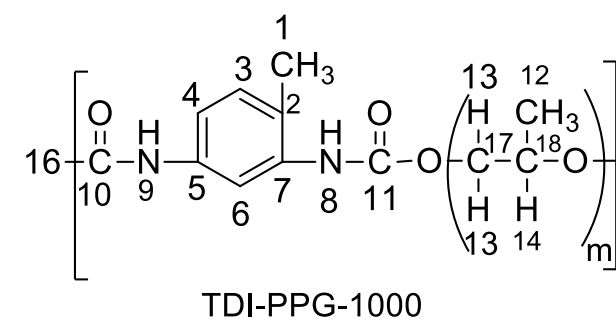 & $\begin{array}{c}17.12 \text { (up) }\left[\mathrm{CH}_{3}-1\right], 17.4 \text { (down) }\left[\mathrm{CH}_{3}-\right. \\
\text { 12], } 71.69 \text { (down) }\left[\mathrm{CH}_{2}-15\right], 72.88 \\
\left.\text { (down) [ } \mathrm{CH}_{2}-17\right], 73.61 \text { (down) }\left[\mathrm{CH}_{2}-\right. \\
16], 127.29 \text { (up) [CH-3], } 130 \text { (up) [CH-4], } \\
131 \text { (up) [CH-6]. }\end{array}$ \\
\hline 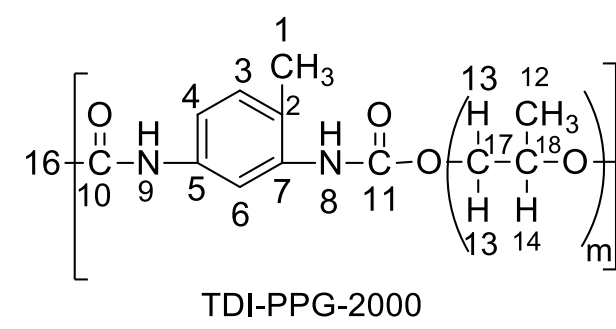 & $\begin{array}{c}17.79 \text { (up) }\left[\mathrm{CH}_{3}-12\right], 20.9 \text { (up) }\left[\mathrm{CH}_{3}-1\right] \\
73.39 \text { (down) }\left[\mathrm{CH}_{2}-17\right], 75.43 \text { (down) } \\
{\left[\mathrm{CH}_{2}-15\right], 77.30 \text { (up) [CH-7],127 (up) }} \\
\text { [CH-3, CH-4], } 131.5 \text { (up) [CH-6]. }\end{array}$ \\
\hline 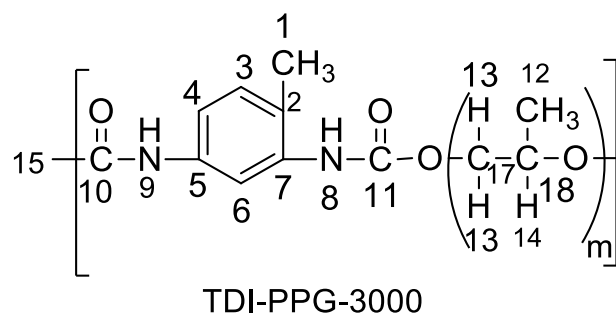 & 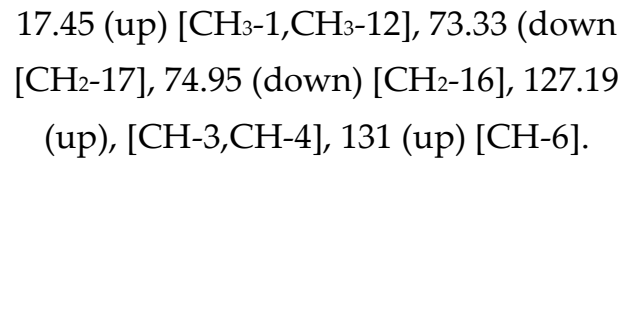 \\
\hline
\end{tabular}
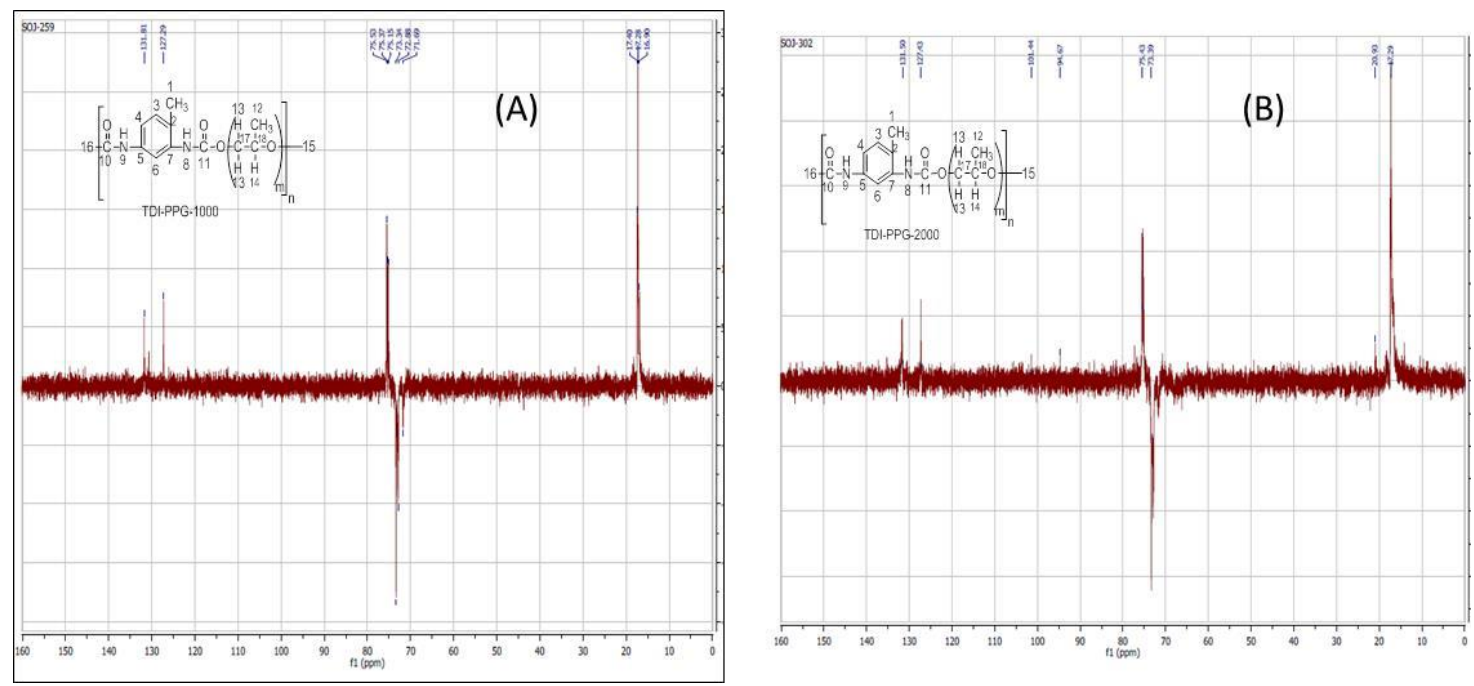

Figure-3. DEPT-135 spectra of (A) TDI-PPG-1000 and (B) TDI-PPG-2000

\subsection{FTIR analysis:}

The FTIR spectra of blocked TDI and polyurethanes are shown in table-6. Figure-4 represents the FTIR spectra of polyurethane. The absence of peak at 2250-2270 $\mathrm{cm}^{-1}$ in 3-(4-bromophenyl) -1H-pyrazole- 
blocked TDI implies that isocyanate group is completely blocked with blocking agent. The absence of peak at $2250-2270 \mathrm{~cm}^{-1}$ in polyurethane implies that isocyanate group is completely blocked in polyurethane. Figure-4 represents the FTIR spectra of TDI-PEG-400 4(a), TDI-PPG-1000 4(b), TDI-PPG-2000 4 (c) and TDI-PPG-3000 4(d).

Table -6. FTIR spectral data of blocked TDI and polyurethane from it

\begin{tabular}{|c|c|c|c|c|c|c|c|}
\hline Compound & $\begin{array}{c}-\mathrm{NH} \\
\text { stretch } \\
\left(\mathrm{cm}^{-1}\right)\end{array}$ & $\begin{array}{l}-\mathrm{NCO} \\
\text { Stretch } \\
\left(\mathrm{cm}^{-1}\right)\end{array}$ & $\begin{array}{c}-\mathrm{C}=\mathrm{O} \\
\text { stretch } \\
\left(\mathrm{cm}^{-1}\right)\end{array}$ & $\begin{array}{c}\mathrm{CH} \\
\text { stretch } \\
\left(\mathrm{cm}^{-1}\right)\end{array}$ & $\begin{array}{c}\text { C-N } \\
\text { Stretc } \\
\quad h \\
\left(\mathrm{~cm}^{-1}\right)\end{array}$ & $\begin{array}{l}\text { C-O- } \\
\text { stretch } \\
\left(\mathrm{cm}^{-1}\right)\end{array}$ & $\begin{array}{c}\mathrm{C}-\mathrm{H} \\
\text { bending } \\
\left(\mathrm{cm}^{-1}\right)\end{array}$ \\
\hline Blocked TDI & 3355 & - & 1730 & 3143 & 1230 & 1000 & 752 \\
\hline TDI-PEG-400 & 3306 & - & 1730 & 2880 & 1230 & 1081 & 781 \\
\hline TDI-PPG-1000 & 3306 & - & 1730 & 2868-2992 & 1230 & 1093 & 756 \\
\hline TDI-PPG-2000 & 3318 & - & 1730 & $2980-2868$ & 1230 & 1081 & 769 \\
\hline TDI-PPG-3000 & 3318 & - & 1730 & $2868-2980$ & 1230 & 1093 & 769 \\
\hline
\end{tabular}
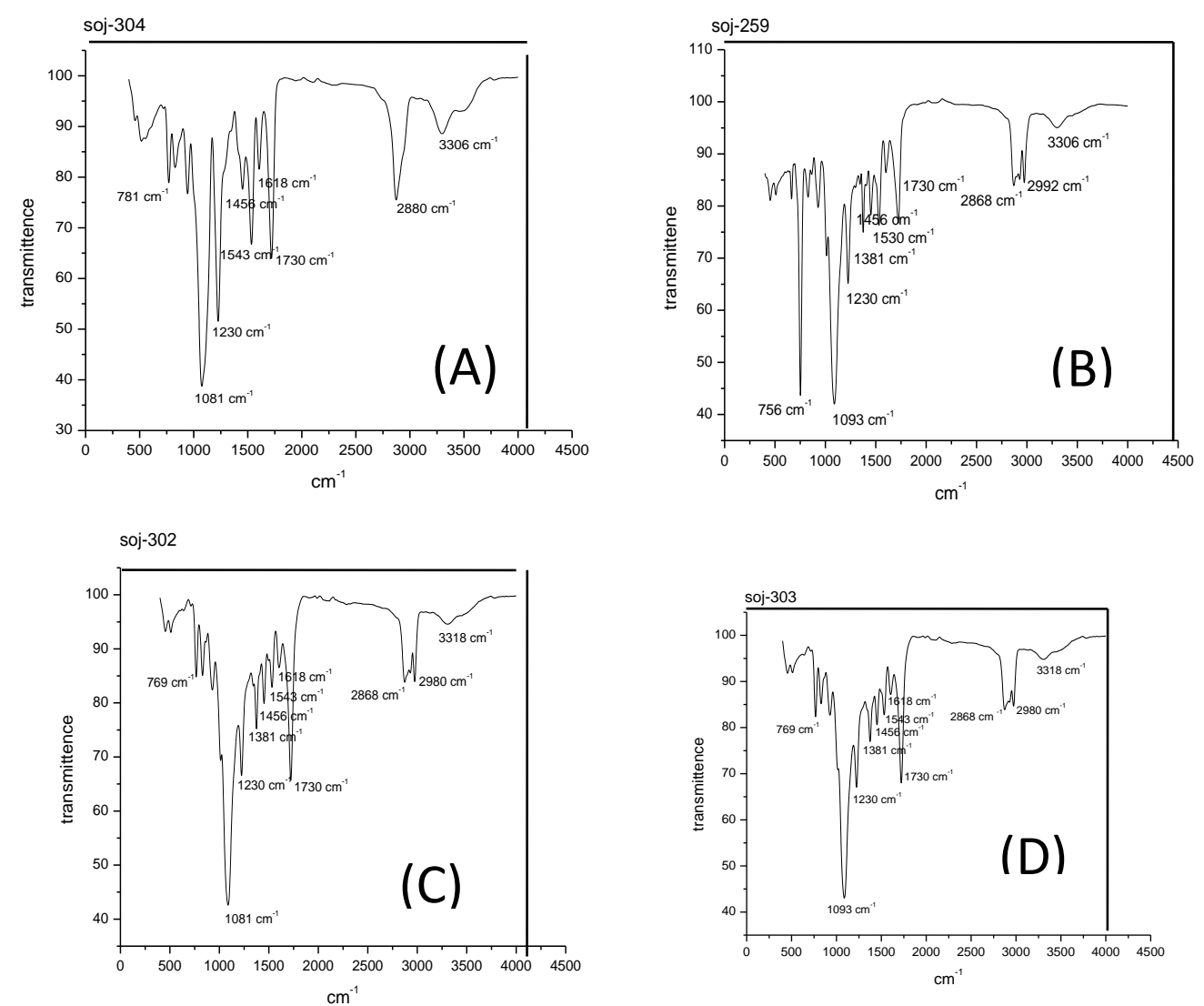

Figure-4. FTIR spectra of (A)TDI-PEG-400 (B) TDI-PPG-1000 (C) TDI-PPG-2000 and (D) TDI-PPG3000. 


\subsection{TGA Thermogram}

The TGA thermograms show the starting point and ending point of blocked isocyanates and polyurethanes that synthesized from blocked TDI. Table-8 show TGA thermogram data of mentioned compounds and Figure- 5 show TGA thermogram of mentioned compounds. TGA thermogram shows that blocked TDI stable upto $160^{\circ} \mathrm{C}$. Polyurethanes are stable upto $200{ }^{\circ} \mathrm{C}$ to $240{ }^{\circ} \mathrm{C}$.

Table-7. TGA thermogram of mentioned compounds.

\begin{tabular}{ccc}
\hline Compound & Starting point & Ending point \\
\hline Blocked TDI & $168.95{ }^{\circ} \mathrm{C}(97.13 \%)$ & $264.48^{\circ} \mathrm{C}(3.121 \%)$ \\
PU-TDI-PEG-400 & $236.63^{\circ} \mathrm{C}(93.47 \%)$ & $514.12^{\circ} \mathrm{C}(14.95 \%)$ \\
PU-TDI-PPG-1000 & $244.9{ }^{\circ} \mathrm{C}(95.46 \%)$ & $454.34{ }^{\circ} \mathrm{C}(68.80 \%)$ \\
PU-TDI-PPG-2000 & $216.92{ }^{\circ} \mathrm{C}(96.06 \%)$ & $535.35^{\circ} \mathrm{C}(30.35 \%)$ \\
PU-TDI-PPG-3000 & $201.00{ }^{\circ} \mathrm{C}(97.31 \%)$ & $521.70{ }^{\circ} \mathrm{C}(14.27 \%)$ \\
\hline
\end{tabular}
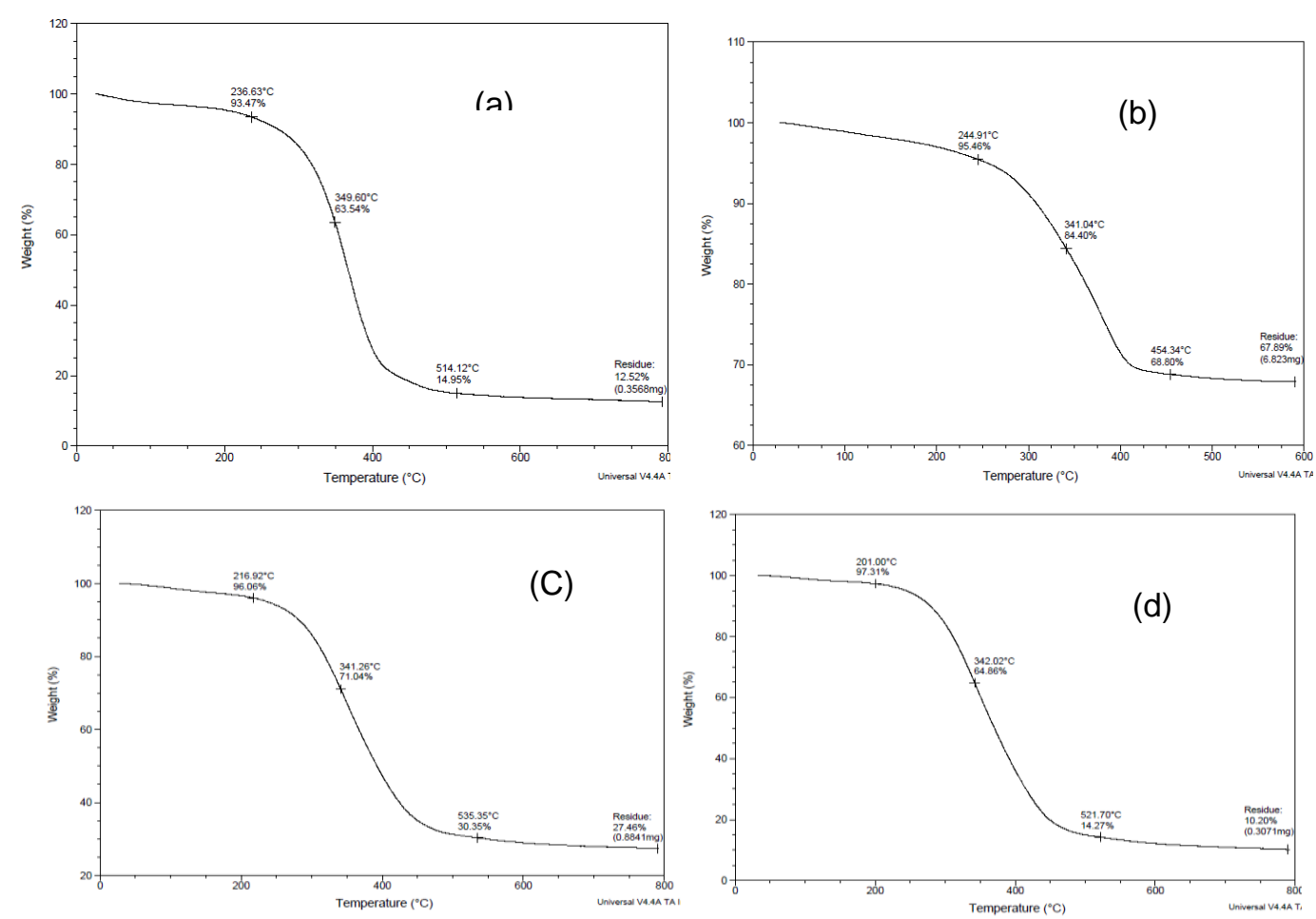

Figure -5. TGA thermogram of (a) TDI-PEG-400 (b) TDI-PPG-1000 (c) TDI-PPG-2000 and (d) TDIPPG-3000.

\subsection{DSC thermogram}

DSC thermogram shows the deblocking behaviours of blocked isocyanates as well as thermal transitions of polyurethanes after deblocking followed by reactions with diols or polyols. As observed from 
Fig 6, while the deblocking temperature was observed at 240 degree $C$, glass transitions were observed in the range of -30 to -40 degree $C$.

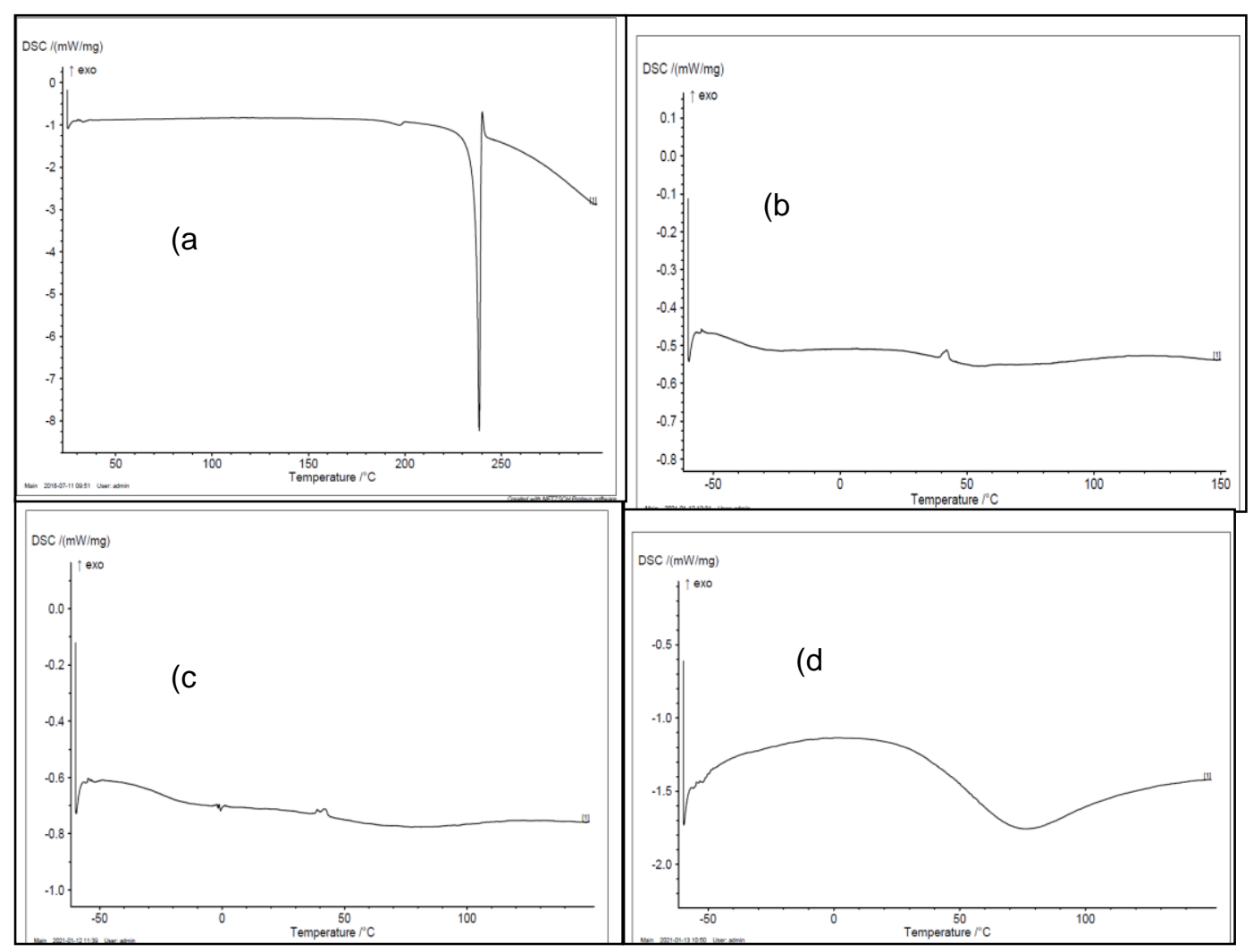

Figure-6. DSC thermogram of (a) blocked TDI, (b) PU-TDI-PPG-1000, (c) PU-TDI-PPG-2000 and (d) PU-PPG-3000.

\subsection{Contact Angle Analysis}

Table-9 shows the contact angle values of polyurethanes. Figure-7 shows the water droplets on surfaces coated with different polyurethanes.

Table-8. contact angle data of polyurethanes.

\begin{tabular}{cc}
\hline Compound & Contact Angle \\
\hline PU-TDI-PPG-1000 & $66.3^{\circ}$ \\
PU-TDI-PPG-2000 & $56.7^{\circ}$ \\
PU-TDI-PEG-3000 & $43.0^{\circ}$ \\
\hline
\end{tabular}




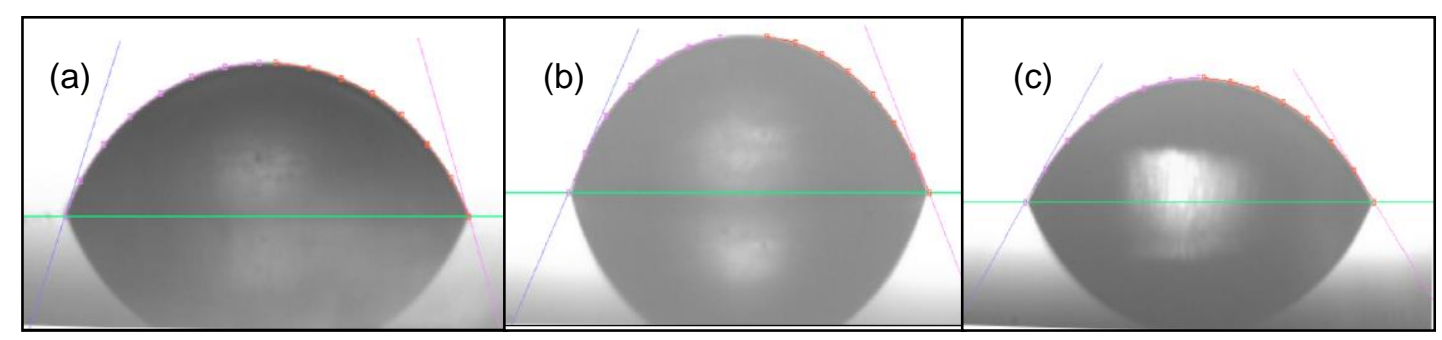

Figure-7. Water droplets on coated surfaces for determining the contact angle of (a) PU-TDI-PPG1000 (b) PU-TDI-PPG-2000 and (c) PU-TDI-PPG-2000

\section{Discussion}

It was generally observed that the Gel time increased as molecular weight of the polyol increased and polyurethane from polyethylene glycol showed better yield than polyurethane from poly propelene glycol. In case of gelation time, PEG-polyurethane has less gelation time than PPG-polyurethane. The $1 \mathrm{H}$ and 13C NMR and DEPT-135 data supported the structures of blocked adduct and polyurethanes. The absence of peak at 2250-2270 cm-1 in 3-(4-bromophenyl) -1H-pyrazole-blocked TDI implies that isocyanate group is completely blocked with blocking agent. Further, the absence of peak at 2250-2270 cm-1 after deblocking in presence of PEG or PPG formation implies the successful formation of polyurethane. TGA thermogram shows that blocked TDI was stable upto $166^{\circ} \mathrm{C}$ and polyurethanes were stable upto $200^{\circ} \mathrm{C}$ to $240^{\circ} \mathrm{C}$. DSC thermogram shows the deblocking behaviours of blocked isocyanates, which indicated that at $240{ }^{\circ} \mathrm{C}$ blocked TDI deblocks. Polyurethane show different glass transition temperatures in which polyurethanes changed glassy state to rubbery state. Contact angle data shows that all synthesized polyurethane compounds are hydrophilic.

\section{Conclusions}

3-(4-bromo-phenyl)-1H-pyrazole was successfully used to block toluene diisocyanate. Spectroscopic data like 1H, 13C NMR and DEPT -135 and FTIR confirm the structure of blocked TDI and polyurethane synthesized from those blocked TDI. This type of blocking is particularly important to conveniently handle toxic substrate like TDI. Further, the blocked isocyanate is stable upto one year. The deblocking and polyurethane formation was conveniently done in a solvent free condition. Contact angle analysis indicates the hydrophilic nature of polyurethane.

Acknowledgments: The authors SNJ and SJ acknowledges CATERS, CSIR-CLRI for TGA sample analysis and Gayathi Varnakumar for contact angle analysis. CSIR-CLRI communication number: A/2021/PLY/MLP/1578.

Conflicts of Interest: The authors declare no conflict of interest 


\section{References}

1. Gite, V. V.; Mahulikar, P. P.; Hundiwale, D. G. Preparation and properties of polyurethane coatings based on acrylic polyols and trimer of isophorone diisocyanate. Prog. Org. Coat. 2010, 68, 307-312.

2. Sang, S. L.; Li, Y. Y.; Wang, K. J.; Tang, J. L. Application of blocked isocyanate in preparation of polyurethane(urea) elastomers. J. Polym. Sci., Part A: Polym. Chem. 2021, 138.

3. Sathiyaraj, S.; Shanavas, A.; Kumar, K. A.; Sathiyaseelan, A.; Senthilselvan, J.; $\quad$ Kalaichelvan, P. T.; Nasar, A. S. The first example of bis(indolyl)methane based hyperbranched polyurethanes: Synthesis, solar cell application and anti-bacterial and anti-oxidant properties. Eur. Polym. J. 2017, 95, 216-231.

4. Tassel, X.; Barbry, D.; Tighzert, L. A new blocking agent of isocyanates. Eur. Polym. J. 2000, 36, 1745-1751.

5. Nasar, A. S.; Jaisankar, S. N.; Subramani, S.; Radhakrishnan, G. Synthesis and Properties of Imidazole-Blocked Toluene Diisocyanates. J. Macromol. Sci. Part A Pure Appl. Chem. 1997, 34, 1237-1247.

6. Dyer, E.; Glenn, J. F.; Lendrat, E. G. The Kinetics of the Reactions of Phenyl Isocyanate with Thiols1. J. Org. Chem. 1961, 26, 2919-2925.

7. Shen, T. F.; Lu, M. G.; Liang, L. Y. Preparation and Properties of Non-ionic Polyurethane Crosslinkers from 2Ethoxyethanol/epsilon-caprolactam-BlockedDiisocyanate. J. Macromol. Sci. Part A Pure Appl. Chem. 2012, 49, 611618.

8. Bertoldo, M.; Cappelli, C.; Catanorchi, S.; Liuzzo, V.; Bronco, S. Understanding theAccelerating Effect of Î $\mu$-Caprolactam on the Formation of Urethane Linkages. Macromolecules 2005, 38, 1385-1394.

9. He, Z. A.; Blank, W. J. Crosslinking with malonate blocked isocyanates and with melamine resins. J. Coat. Technol. 1999, 71, 85-90.

10. Carter, J. W.; Pappas, S. P. A Novel Design Strategy for Blocked Isocyanates to Enhance Their Reactivity with Alcohols - Oxime Blocking-Agents Which Undergo Intramolecular Cyclization. J. Coat. Technol. 1992, 64, 2936.

11. Zhou, Z.; Lv, H.; Wang, X.; Ren, F.; Xu, W. Deblocking of the water-soluble isophorone diisocyanate blocked by sodium bisulfite and its application. J. Appl. Polym. Sci. 2013, 128, 597-599.

12. Nasar, A. S.; Subramani, S.; Radhakrishnan, G. Synthesis and properties of aromatic secondary amine-blocked isocyanates. J. Polym. Sci., Part A: Polym. Chem. 1999, 37, 1815-1821.

13. Jana, S.; Ramar, P.; Samanta, D.; Jaisankar, S. N. Bromo-substituted blocked hexamethylene diisocyanate adduct: synthesis, characterization and application toward polyurethane coating. J. Macromol. Sci. Part A Pure Appl. Chem. 2020, 58, 298-308.

14. Mulebach, A. Pyrazoles-A novel class of blocking agents for isocyanates. Journal of Polymer Science Part A: Polymer Chemistry 1994, 32, 753-765.

15. Shen, T. F.; Zhou, D. W.; Liang, L. Y.; Zheng, J.; Lan, Y. X.; Lu, M. G. Synthesis and Characterization of Reactive Blocked-Isocyanate Coupling Agents from Methyl Ethyl Ketoxime, Ethyl Cellosolve/epsilon-Caprolactam Blocked Aromatic and Aliphatic Diisocyanates. J. Appl. Polym. Sci. 2011, 122, 748-757.

16. Nasar, A. S.; Shrinivas, V.; Shanmugam, T.; Raghavan, A. Synthesis and deblocking of cardate-blocked toluene diisocyanates. J. Polym. Sci., Part A: Polym. Chem. 2004, 42, 4047-4055.

17. Zhang, Z. W.; Peng, P. P.; Wu, Q. Y.; Zhang, J. A.; Wu, M. Y.; Liu, J. Y.; Yang, J. J. Preparation and antibacterial properties of poly(hexamethylene guanidine hydrochloride) modified ionic waterborne polyurethane. Prog. Org. Coat. 2021, 156.

18. Zhang, F. Y.; Liu, W. Q.; Liang, L. Y.; Wang, S.; Shi, H. Y.; Xie, Y. K.; Yang, M. P.; Pi,K. The effect of functional graphene oxide nanoparticles on corrosion resistance of waterborne polyurethane. Colloids Surf., A 2020, 591.

19. Ahmad, I.; Zaidi, J. H.; Hussain, R.; Munir, A. Synthesis, characterization and thermal dissociation of 2-butoxyethanol-blocked diisocyanates and their use in the synthesis of isocyanate-terminated prepolymers. Polym. Int. 2007, 56, 1521-1529.

20. Delebecq, E.; Pascault, J.-P.; Boutevin, B.; Ganachaud, F. o. On the Versatility of Urethane/Urea Bonds: Reversibility, Blocked Isocyanate, and Non-isocyanate Polyurethane. Chem. Rev. 2013, 113, 80-118.

21. Ranjbar, Z.; Montazeri, S.; Nayini, M. M. R.; Jannesari, A. Synthesis and characterization of diethylene glycol monobutyl ether-Blocked diisocyanate crosslinkers. Prog. Org. Coat. 2010, 69, 426-431.

22. Shen, T. F.; Sun, Y. J.; Sun, C. F.; Lu, M. G. Preparation and Characterization of Polyurethane Bioadhesive from Hydroxyl-terminated Polylactide and Imidazole- blocked Isocyanate. Polymer-Korea 2013, 37, 232-239.

23. Muelebach, A. Pyrazoles - A novel class of blocking agents for isocyanates. J. Polym. Sci., Part A: Polym. Chem. 1994, 32, 753-765.

24. Prakash, D.; Jaisankar, S. N. Thermoplastic poly(urethane-thiourethane) triblock copolymers with SWCNTs composite. Diamond Relat. Mater. 2019, 93, 34-41. 
25. Murali, A.; Gurusamy-Thangavelu, S. A.; Jaisankar, S. N.; Mandal, A. B. Enhancement of the physicochemical properties of polyurethane-perovskite nanocomposites via addition of nickel titanate nanoparticles. RSC Adv. 2015, 5, 102488-102494.

26. Meera, K. M. S.; Sankar, R. M.; Paul, J.; Jaisankar, S. N.; Mandal, A. B. The influence of applied silica nanoparticles on a bio-renewable castor oil based polyurethanenanocomposite and its physicochemical properties. Phys. Chem. Chem. Phys. 2014, 16, 9276-9288.

27. Sankar, R. M.; Meera, K. S.; Mandal, A. B.; Jaisankar, S. N. Thermoplastic polyurethane/single-walled carbon nanotube composites with low electrical resistance surfaces. High Perform. Polym. 2013, 25, 135-146.

28. Mustapha, S.; Andou, Y. Enhancing Mechanical Properties of Polyurethane with Cellulose Acetate as Chain Extender. Fibers Polym. 2021.

29. Gu, L.; Wu, Q. Y. Recyclable bio-based crosslinked polyurethanes with self-healing ability. J. Appl. Polym. Sci. 2018, 135.

30. Xie, F. W.; Zhang, T. L.; Bryant, P.; Kurusingal, V.; Colwell, J. M.; Laycock, B. Degradation and stabilization of polyurethane elastomers. Prog. Polym. Sci. 2019, 90, 211-268.

31. Mukherjee, M.; Gurusamy-Thangavelu, S. A.; Chelike, D. K.; Alagumalai, A.; Das, B. N N.; Jaisankar, S. N.; Mandal, A. B. Biodegradable polyurethane foam as shoe insole to reduce footwear waste: Optimization by morphological physicochemical and mechanical properties. Appl. Surf. Sci. 2020, 499. 